\title{
Arte visionária e surrealismo: estabelecendo relações comparativas
}

\author{
Visionary art and surrealism: establishing comparative relations
}

Rômulo Nery Silvério Machadoํㅗㄴ Marta Dantas da Silva²

\section{Resumo}

O presente artigo visa uma breve explanação sobre a Arte Visionária, seu surgimento, algumas de suas características, alguns de seus representantes e suas possíveis relações com a arte surrealista. Por meio de pesquisa bibliográfica, apresentamos um breve estudo comparando os aspectos formais, temática e fonte de inspiração de representações tidas como surrealistas e outras como visionárias. Compreendemos que o interesse pelo desconhecido é um ponto em comum, e que as divergências entre a Arte Visionária e o Surrealismo estão, sobretudo, relacionadas a valorização do espiritual, por parte da arte visionária.

Palavras-chave: Arte visionária. Espiritual. Surrealismo.

\begin{abstract}
The present article aims a brief explanation about the Visionary Art, its emergence, some of its characteristics, some of its representatives and its possible relations with the surrealist art. By the bibliographic research method, we present a brief study comparing the formal aspects, thematic and source of inspiration of representations taken as surrealist and others taken as visionary. We comprehend that the interest by the unknown is a common point, and that the divergences between the Visionary Art and the Surrealism are, mostly, related to the valorization of the spiritual, that aims the Visionary Art.

Keywords: Visionary art. Spiritual. Surrealism.
\end{abstract}

\section{Introdução}

Desde os primórdios da humanidade existiu algo bastante potente que aproximava arte e espiritualidade, manifestado através de imagens em cavernas, templos, objetos, entre outros. E será que essa aproximação que houve entre arte e espiritualidade ainda pode ser encontrada hoje? É a partir da resposta afirmativa a esta pergunta que podemos pensar no que hoje se chama Arte Visionária. Partindo de grande interesse pessoal pelo assunto, e a fim de aprofundar o conhecimento sobre o mesmo, buscou-se compreender melhor o que é a Arte Visionária, por meio de aproximações e distanciamentos com o movimento surrealista. Para isso, lançamos mão da pesquisa bibliográfica, e tomamos como base autores mais influentes sobre os assuntos, como o próprio entusiasta do movimento surrealista André Breton, e o professor, pesquisador e artista José E. Mikosz, entre outros.

Contextualizando o movimento surrealista e a Arte Visionária, e buscando relações comparativas, buscou-se, mesmo que brevemente, refletir sobre

\footnotetext{
1 Bacharel em Administração pela UEM e graduando em Artes Visuais pela UEL. E-mail: romulo0o@hotmail.com

2 Doutora em Sociologia pela UNESP e pós doutora em Literatura Brasileira pela USP. Professora Associada do Departamento de Arte Visual e do Programa de Pós-Graduação em Letras da UEL, atua na subárea de História e Teorias da Arte e, sobretudo, com questões relacionadas ao Surrealismo.E-mail: marta_dantas@hotmail.com
} 
uma área pouco estudada na história da arte, o da Arte Visionária, que envolve questões complexas e controversas, pois adentram o âmbito dos Estados Não Ordinários de Consciência (ENOC) e do espiritual.

Não visamos nesse trabalho investigar quaisquer definições do que seja espiritual ou do que chamamos de inconsciente, mas refletir sobre o que se compreende por Arte Visionária. A aproximação com o Surrealismo nos auxiliará nesta reflexão na medida em que compartilham grande interesse pelo desconhecido e pela sua representação.

\section{O Surrealismo}

A primeira metade do século XX é marcada por duas grandes guerras e, como consequência, por uma crise de valores e de concepção de mundo. No período entre essas guerras surge, no campo das artes, alguns movimentos artísticos engajados numa revolução estética: e conhecidos como as vanguardas históricas, a saber: o Cubismo, o Futurismo, o Dadaísmo, entre outros. Entre esses movimentos um se destaca pela sua abrangência, por ultrapassar o campo artístico e literário, e adentrar o político e, sobretudo, a própria vida: o Surrealismo:

"A vontade do surrealismo de irromper na história, inclusive na atividade política, para criar as condições da liberdade material e espiritual do homem, é uma vontade moderna, a única vontade capaz de trazer a cultura para lá da crise, de volta, a um terreno criativo diferente, onde a fratura [entre arte e vida] seja reparada, não com a repetição de uma visão ultrapassada, mas com a força de uma visão renovada". (DE MICHELI, 2004, p. 153).

Seu lema era "transformar o mundo", como pretendia Karl Marx, e, ao mesmo tempo, "mudar a vida", como dizia o poeta Arthur Rimbaud. Na base de suas proposições encontramos dois teóricos: Marx, porque pensou na revolução social, e Freud, porque apresentou os caminhos para a revolução individual.
Os surrealistas viam as ideias de ambos como meios de criticar a ordem social existente e a cultura dominante, vista por eles como repressiva. Esse estado de repressão, acreditavam, possuía tanto uma dimensão psíquica quanto social. Atualmente, com frequência, o marxismo e a psicanálise são vistos como polos opostos, um relacionado aos determinantes econômicos e sociais da vida em sociedade, e a outra associada a um domínio associal, psíquico do inconsciente. Contudo, em alguns momentos no passado, ambos foram considerados formas radicais de questionamento e relacionados entre si, ainda que de forma complexa. O Surrealismo é um desses momentos históricos. (FER, 1998, p. 180)

André Breton foi o teórico desse movimento que se iniciou, oficialmente, com a publicação do Manifesto do Surrealismo de 1924, em que exaltava essa busca por liberdade: "A palavra liberdade é a única que ainda me exalta. Considero-a apta a sustentar, indefinidamente, o velho fanatismo humano. Ela responde, sem dúvida alguma, a minha única aspiração legítima" (BRETON, 2004, p. 17). A busca por liberdade estava tanto no âmbito social quanto individual, o que culminou em um movimento bastante diversificado em suas experimentações.

Desde o início, o Surrealismo era um movimento heterogêneo. Incluía escritores, pintores, poetas e fotógrafos; mais tarde, no final dos anos 20, diversificou-se na produção de objetos e filmes. Além disso, os surrealistas produziram uma grande quantidade de revistas, utilizando-as como plataforma para debate. Mesmo se nos restringirmos à pintura surrealista, concluiremos que nunca houve uma unidade de estilo. Por exemplo, os surrealistas jamais recomendaram que se atribuísse maior valor à arte abstrata, ou à figurativa. Pinturas que pareciam muito diferentes em termos formais - tais como Pintura, de Joan Miró, de 1927; e As acomodações de desejos, de Salvador Dali, de 1929 - podiam ser vistas como parte de um mesmo projeto. (FER, 1998, p. 171). 
Figura 1 - Joan Miró, Painting

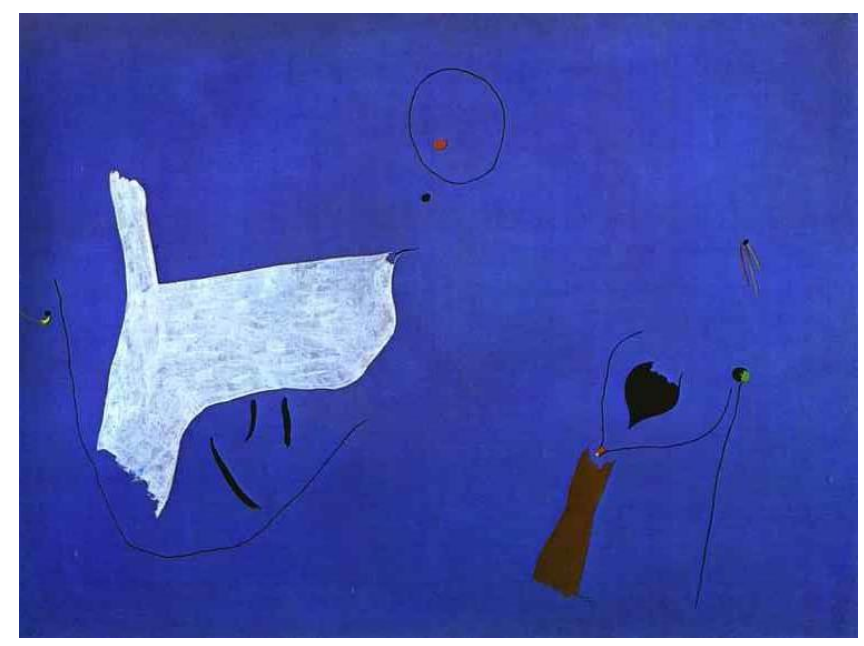

Fonte: Tate (2018).

A liberdade era, primeiro, libertar-se das travas da razão, por isso os sonhos, a loucura e o que poderia ser chamado de místico interessava aos surrealistas, tudo que de alguma forma sofria alguma repressão psicológica e consequentemente social, deveria emergir da obscuridade dos pensamentos e ser expressado. Os surrealistas apostavam "na crença, na realidade superior de certas formas de associação até aqui negligenciadas, na onipotência do sonho, no jogo desinteressado do pensamento" (BRETON, 2004, p. 40). No Manifesto do Surrealismo de 1924, Breton (2004, p. 40) assim define o movimento:

"Surrealismo, s.m. Automatismo psíquico em estado puro mediante o qual se propõe exprimir, verbalmente, por escrito ou por qualquer outro meio, o funcionamento do pensamento. Ditado do pensamento, suspenso qualquer controle exercido pela razão, alheio a qualquer preocupação estética ou moral".

"A escrita e a arte surrealistas não se definem nem por um estilo, nem por uma feitura" (CHÉNIEUXGENDRON, 1992, p. 188). Repleto de contradições e mistérios, impulsionando a liberdade externa através de um mergulho no desconhecido interior, negado pelo modelo de sociedade vigente até então, o Surrealismo se propunha a "levantar-se contra a 'dissolução' do espírito [e] devolver à consciência individual uma função participativa, tal é o papel a que se dedica o surrealismo em suas últimas décadas" (CHÉNIEUX-GENDRON, 1992, p. 35).

$\mathrm{O}$ interesse pelo desconhecido, esse inconsciente reprimido, detentor de grande potência de vida, tem grande relevância dentro do Surrealismo, e é essa força de investigação da mente que contribuiria para a conquista da liberdade, como disse Breton (2004, p. 24):

"Se as profundezas de nossa mente albergam estranhas forças, capazes de aumentar as forças da superfície ou de lutar vitoriosamente contra elas, é do maior interesse capturá-las: capturá-las para em seguida, se for o caso, submetê-las ao controle da razão".

O sonho, para os surrealistas, é considerado uma parte essencial a existência, e não inferior ao estado de vigília, pois é onde o indivíduo pode realizar seus desejos reprimidos e se satisfazer plenamente, e é a aproximação desse universo inconsciente com o consciente, aparentemente tão contraditórios, que faria o ser humano livre. Como explica De Micheli (2004, p.157), “é preciso encontrar os modos para 
fazer com que a voz enterrada do nosso espírito, aquela voz que as convenções mais brutais tentam reprimir, intervenha na vida dissipada dos nossos dias". Há a investigação da infância, um olhar para dentro de si mesmo, afim de libertar-se de todas as amarras geradas pelo passado, recalcadas inconscientemente através do tempo. Esse inconsciente, segundo Fer (1998, p. 181):

É considerado por Freud como tendo sua própria estrutura e modos de expressão, que são diversos daqueles que atuam no nível consciente. Ele tem seus próprios impulsos, que são revelados apenas em algumas ocasiões e de modo necessariamente indireto. $\mathrm{O}$ inconsciente, para Freud, referese também à infância - o que foi reprimido em tenra idade pela nossa parte inconsciente. Para compreender os mecanismos do inconsciente, os surrealistas exploraram a linguagem e os processos de funcionamento do sonho. Olharam para dentro de si mesmos em busca do que era infantil, mas também exploraram os lapsos de memória, as repressões de toda uma cultura; voltaram-se para o passado, ou para os mitos ancestrais, com o intuito de questionar o presente e imaginar uma saída para as condições atuais - como um meio de transgredir as fronteiras estabelecidas da representação.

É nesse aspecto, o da aproximação do estado de vigília com o sonho, que se encontra a revolução individual apontada por Breton, portanto, "o surrealismo se define como uma atitude do espírito ante a realidade e a vida, não como um conjunto de regras formais, de medidas estéticas" (DE MICHELI, 2004, p. 170).

Desse mergulho em profundezas desconhecidas, de busca interior, é que podemos estabelecer elos e também perceber distanciamentos com a Arte Visionária. Segundo Breton (2004, p. 18) “a verdade é que as alucinações, as ilusões, etc., constituem uma fonte considerável de prazer", mas ainda que haja uma investigação interior, os visionários não percebem suas experiências enquanto alucinações ou ilusões, e tampouco enquanto uma busca por prazer, como será visto adiante.

Para os surrealistas, o interior não é algo espiritual, nem algo separado do exterior, mas sim a própria vida que jaz em desencanto e precisa ser encantada novamente. A arte surrealista tende então a um objetivo, "a criação de um mundo em que o homem encontre o maravilhoso, um reino do espírito onde ele se liberte de toda gravidade e inibição, de todo complexo, atingindo uma liberdade inigualável, incondicionada" (DE MICHELI, 2004, p. 160).

\section{A Arte Visionária}

A Arte Visionária não deve ser compreendida enquanto um movimento histórico como o Surrealismo, mas enquanto um fenômeno em cadeia que perpassa toda a história da arte, pois como será visto adiante, em toda a história da arte sempre houve artistas visionários e, vez ou outra, dentro de determinado período histórico, movimento artístico ou fase da vida de algum artista, surgiram trabalhos visionários, como diz Caruana (2013, p. 7):

A Arte Visionária é tão antiga quanto os primeiros registros feitos nas paredes das cavernas pelos xamãs ou as misteriosas espirais esculpidas nas rochas megalíticas. Nossa arte está presente entre os egípcios, mesopotâmicos, minoicos e os antigos gregos. Na América Central, se desenvolveu entre os Astecas, Maias e Olmecas. No Oriente ela atingiu um alto grau de refinamento na arte Hindu e Budista.

Segundo Mikosz (2014, p. 95), a Arte Visionária tem como objetivo "transcender o mundo físico, retratar visões que muitas vezes incluem temas espirituais e místicos ou, pelo menos, alicerçadas em tais experiências", mas nem sempre os ENOC são fruto de experiências espirituais, pois qualquer outro estado além do estado de vigília, pode ou não ser considerado ENOC, e é um ponto como esse 
que pode tanto aproximar como distanciar a arte surrealista da Arte Visionária, como em Caruana (2013, p. 35):

As fontes de experiência visionária são muitas e variadas: sonhos, sonhos lúcidos, pesadelos, imagens hipnagógicas, sonhos acordados, estados de transe (provocada pela exaustão, a privação ou a repetição rítmica de orações ou música), estados hipnóticos, de doença, experiências de quase morte, buscas xamânicas de visão, meditação (com os olhos fechados ou focalizado sobre uma imagem sagrada), loucura (seja temporariamente - devido a traumas da vida - ou permanente), o devaneio, a fantasia, a imaginação, inspiração, visitação, revelação, visões espontâneas, psicodélicos, leituras e - não podemos esquecer - a experiência metanoica trazida pela Arte Visionária em si.
Mas ao se falar deArte Visionária hoje, certamente a referência são alguns artistas do período após a $2^{\mathrm{a}}$ Grande Guerra, que buscavam, através de técnicas minuciosas e do resgate aos ensinamentos de velhos mestres, trazer à tona visões internas, por vezes espirituais, inspirados pelos ENOC.

Hutter, Lehmden e Brauer, e particularmente Ernst Fuchs, tentaram reviver as técnicas de antigos mestres da pintura, combinando-as com as teorias das cores dos impressionistas, se dedicando, com esses novos artifícios e precisão, aos temas fantásticos. Como muitos desses artistas ainda estão vivos atualmente, eles se tornaram conhecidos como visionários da 'primeira geração (CARUANA, 2013, p. 12).

Figura 2 - Ernst Fuchs, Transformationss of the Flesh

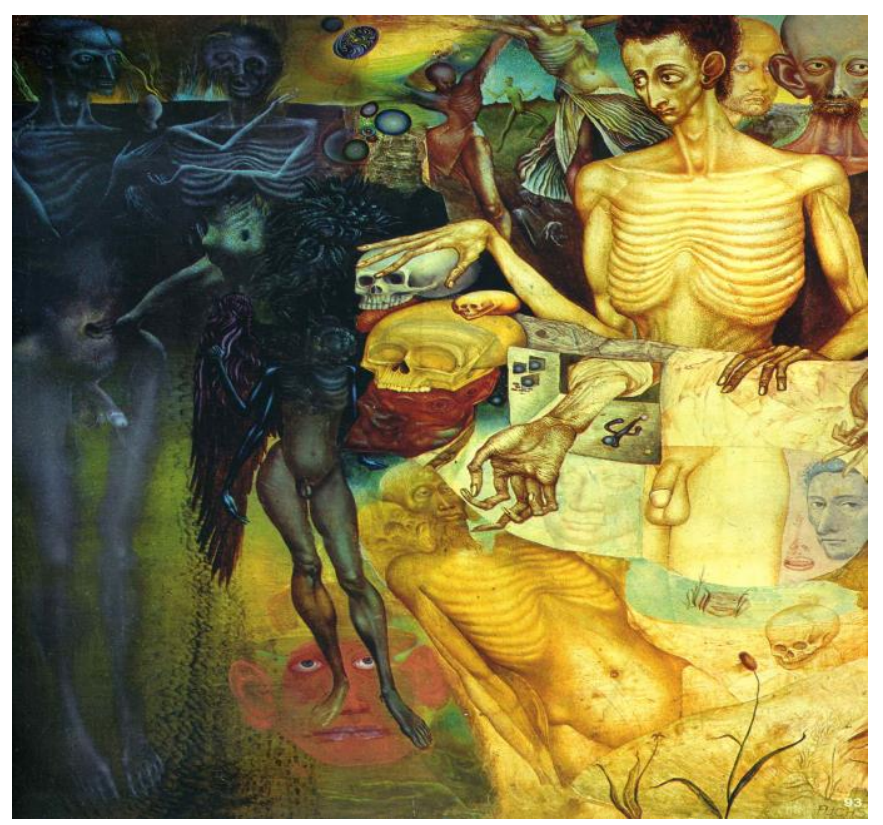

Fonte: Site Wikiart

Embora Caruana os designe como visionários, esse grupo de artistas, todos austríacos, alguns ainda vivos, são fundadores e cofundadores da Vienna
School of Fantastic Realism (Escola de Vienna de Realismo Fantástico). E ainda segundo Caruana (2013, p. 12) sobre o legado da Arte Visionária: 
Sob a orientação espiritual de Fuchs, surgiu uma segunda geração de artistas nas décadas de 1960, 1970 e 1980. Fuchs ensinava a esses artistas a técnica de Mischtechnik (nome dado pelo pesquisador de materiais artísticos Max Doerner). Uma ligação direta pode ser traçada de Fuchs até Mati Klarwein, De Es Schwertberger e Robert Venosa.

Após a difusão dos trabalhos da Escola de Vienna, hoje em dia, principalmente devido a fatores de globalização como a internet, os artistas visionários, em sua maioria, sentem-se atraídos pela técnica Mischtechnik empregada por Fuchs, e antigamente, também pelos chamados "velhos mestres", como Leonardo DaVinci. Como descrito resumidamente por Caruana (2013, p. 56) a Mischtechniké aplicada da seguinte forma:

No começo, o quadro é pintado uma série de camadas alternadas entre branco de têmperaovo e veladuras óleo-resinosas coloridas. Primeiramente, uma cor de base escura é colocada sobre o desenho (a imprimatura - geralmente em vermelho, violeta, ou caput mortuum) e as formas são, então, definidas de acordo com uma emulsão de branco de têmpera-ovo (pintada sobre base úmida).

[...]

O Mischetechnik, na sua forma mais básica, passa por quatro fases correspondentes: vermelho na imprimatura, seguido pela veladura amarela em primeiro lugar, pela azul em segundo e, finalmente, pelas 'cores locais'.

A técnica Mischtechnik não pode ser tida como uma característica determinante da Arte Visionária, até mesmo por que se pensarmos nesse fenômeno em toda história da arte, haverá Arte Visionária nas mais diversas técnicas, mas é de grande importância o seu conhecimento para compreender a Arte Visionária atual, pois parece haver um grande interesse pelos artistas visionários nessa técnica, devido as possibilidades de se explorar os efeitos visuais de cor e luz, que podem se aproximar do que é experienciado e visto em ENOC e auxiliar na representação. Como dito anteriormente, a Arte Visionária nunca foi um movimento, mas hoje pode ser confundido como tal, principalmente devido a esse fator da técnica empregada pela maioria dos artistas.
Figura 3 - Ana Suromai

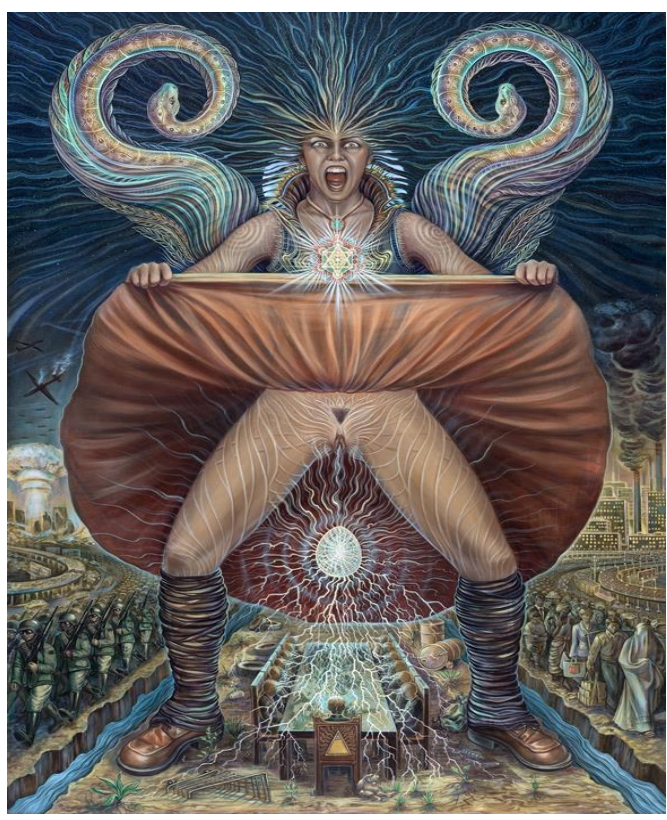

Fonte: Sage (2018)
Figura 4 - Amasifuen, Flor de Tabacco II

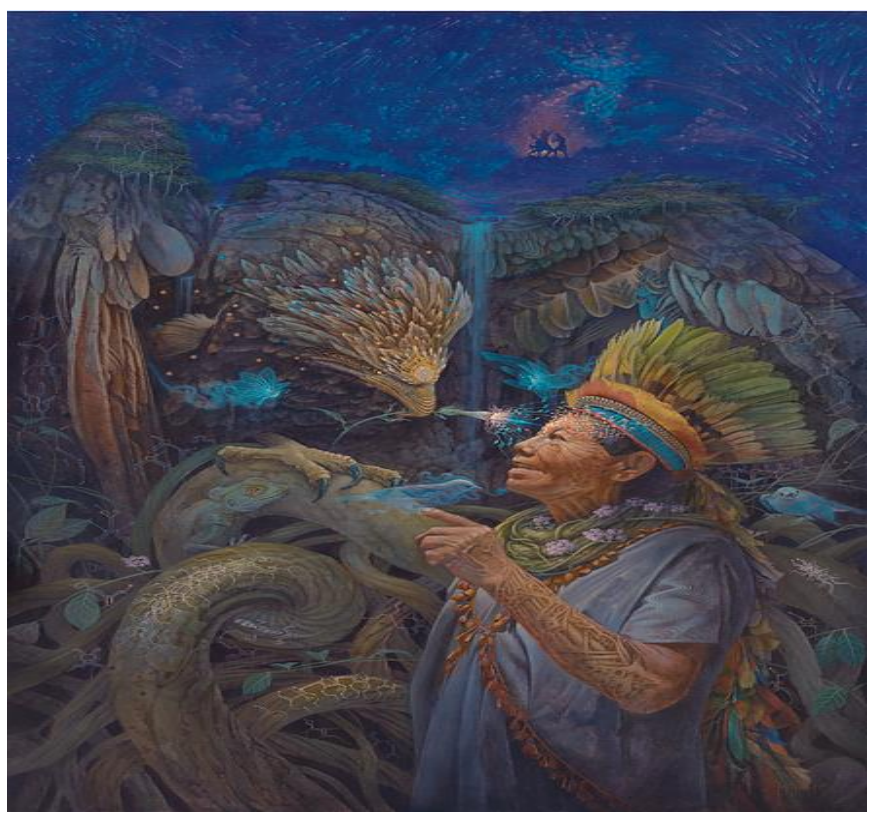

Fonte: Tamani (2018). 
É bastante complexo descrever exatamente do que se tratam os estados não ordinários de consciência, pois quando se entra no âmbito do que não é racional, que pode ou não ser designado como espiritual, qualquer definição metódica acaba por fazer ruir a grandiosidade das experiências. Tratase de uma situação paradoxal, além de quaisquer limitações ou definições. Todavia, partindo de uma perspectiva de estudos na área da psicologia, Mikosz (2014, p. 18) diz que "essas visões, nos estágios iniciais, podem se apresentar como formas geométricas diversas, coloridas e luminosas. Em estágios mais avançados, essas visões podem dar lugar a cenas de maior complexidade". E ele acrescenta:

Deve-se levar em consideração que muitas sensações diferentes, não apenas as visuais, estão presentes nos ENOC. Por exemplo, uma dificuldade em respirar, somada a visões distorcidas, sensação de flutuar, sons, pode parecer para o indivíduo uma experiência de submersão na água, e nem sempre serão representadas em desenhos e pinturas essas vivências" (MIKOSZ, 2014, p. 55).

É possível se distanciar do âmbito espiritual e tratá-los como algo inconsciente, ou simplesmente, desconhecido, e uma representação inspirada em tal estado não deixaria de ser visionária, ainda que não esteja relacionada a algo que possa ser considerado espiritual. Todavia, é importante perceber como na Arte Visionária os temas e as visões são tratados com grande seriedade, pois se trata de experiências genuínas do artista e por isso "as experiências de ENOC preenchem uma lacuna que torna possível encarar o fenômeno religioso e da fé por um novo viés, ou seja, como uma característica intrínseca da natureza humana, a Arte Visionária, como um dos meios de expressá-la” (MIKOSZ, 2014, p. 214).

Das muitas formas de se atingir os ENOC, o uso ritualístico, xamânico ou religioso de plantas e fungos psicoativos, aparenta ser um método mais direto e frequente entre os artistas visionários, e como descrito por Mikosz (2014, p. 44):

O uso de psicoativos como psilocibina, DMT (N, N-dimetiltriptamina), LSD, ácido ibotêmico presente no cogumelo Amanita muscaria, o iboga africano, a ayahuasca, mescalina, etc. Trata-se aqui dos psicoativos da classe phantastica ou, vulgarmente, alucinógenos, também chamados de drogas psicodélicas, lembrando que a palavra alucinógeno e droga carregam de antemão forte carga pejorativa, cercada de muita desinformação e preconceito. A palavra droga é geralmente usada para associar a substâncias prejudiciais a saúde, perigosas e ilícitas.

Ainda que nem todo ENOC proporcione uma experiência espiritual, e nem toda Arte Visionária seja de cunho espiritual, a maior parte da história da arte se preocupou em produzir representações do que pode-se chamar de espiritual, de visões transcendentais, em pinturas, objetos e construções arquitetônicas que fizessem presente o divino diante da vida de cada indivíduo, de maneiras diversas, oriundas de culturas diversas, mas de alguma forma em união com um todo em comum, alcançado através de um mergulho no interior do próprio criador de arte.

É da representação inspirada pelo contato direto com estados não ordinários de consciência que brota a Arte Visionária, um tipo de arte com raízes longínquas na história, mas que se faz fortemente presente em diversos países pelo mundo, ganhando maior visibilidade graças a $O$ Primeiro Manifesto da Arte Visionária, de Laurence Caruana, publicado originalmente em 2001.

\section{Relações Comparativas}

A Arte Visionária, como conhecemos hoje, estende suas raízes diretamente ao Surrealismo, mas apenas uma parcela deste movimento ramificou-se em inspiração para os artistas visionários, de acordo com Caruana (2013, p. 10): 
O Surrealismo pode, sem dúvida, ser identificado como tendo influência direta sobre a Arte Visionária, porém, dois ramos distintos desse movimento devem ser separados e identificados. Um deles, o automatismo, possui maior tendência em torno da forma e da abstração, por exemplo: Miró, Arp, Tanguy e Matta. [...] Com estes, a Arte Visionária tem menos em comum. $\mathrm{O}$ outro, Surrealismo Figurativo, tendendo mais para a representação precisa e plástica de sonhos e de suas imagens na pintura. Aqui, Picasso, Ernst, Magritte, Delvaux, Bellmer, Fini, e particularmente Dali, devem ser considerados como os antepassados da Arte Visionária contemporânea.

Os artistas surrealistas não produziam apenas pintura, mas devido a ser um meio mais comum para a representação, aparentemente de maior interesse pelos artistas visionários atualmente, partir da pintura parece ser mais apropriado para traçarmos comparações entre Surrealismo e Arte Visionária, pois é possível tomar como base a questão da representação, que é fundamental à Arte Visionária, e para os surrealistas como afirma De Micheli (2004, p. 164):

Ao falar em arte surrealista deve-se desde logo observar que se trata sempre de uma arte de figuração. $\mathrm{O}$ abstrato, especialmente o abstrato geométrico ou construtivista, não se encaixa na natureza do surrealismo, cujos extremos menos figurativos, Arp e Miró, estão muito longe de serem classificáveis como abstratos. Isso porque não se pode ser surrealista sem se empenhar de alguma maneira numa representação.

A heterogeneidade da produção artística do movimento surrealista, como colagens, frotagens, montagens, objetos tridimensionais, fotografias, cinema, também se faz presente entre os artistas visionários, além de esculturas, instalações, performances, arte digital, mas na arte surrealista há uma exploração do próprio fazer entre as diversas linguagens, enquanto que na arte visionária, ainda que possa haver a exploração da materialidade e da linguagem poética em si, na maioria das vezes isso estará condicionado de alguma forma a experiências prévias em ENOC.

O ponto mais importante, e crucial na diferenciação entre Arte Visionária e Surrealismo é a relação com o espiritual, como diz Mikosz (2014, p. 167), "uma das principais diferenças entre o Surrealismo e a Arte Visionária está na abordagem espiritual, negada pelo radicalismo ateísta dos surrealistas, mas bem-vinda na experiência dos visionários".

Há uma preocupação em um resgate de atualização, por parte dos artistas visionários atualmente, em relação aos velhos mestres da pintura, cujos processos artísticos apresentam forte relação com o espiritual, sobretudo aqueles pertencentes ao Renascimento. Apenas como uma recorrência a ferramentas técnicas para que a representação das visões se faça possível.

Um ponto discordante em relação ao Surrealismo é o uso da arte como instrumento político de transformação social; isso não é um objetivo motriz na Arte Visionária. Mas isso também não é regra, não há um discurso político dominante, pois, as diversas visões políticas dos artistas também podem aparecer em suas obras, como críticas ao sistema capitalista ou o posicionamento feminista de artistas mulheres, por exemplo.

Tanto os surrealistas quanto os visionários estão trabalhando a aproximação de duas realidades, ou tentando romper com a dualidade nesses estados tidos como aparentemente opostos, e no caso das artes visuais isso poderia acontecer através da imagem, como afirmou Breton (2004, p. 28): “será possível reduzir esses dois estados aparentemente tão contraditórios, que são o sonho e a realidade, a uma espécie de realidade absoluta, de sobrerealidade, se é lícito chamá-la assim". Todavia, para os visionários, segundo Mikosz (2014, p. 97):

"Retratar experiências vividas nos sonhos não significa propriamente fazer arte visionária; os 
sonhos não são considerados ENOC, salvo, como visto, os sonhos lúcidos ou proféticos, mas, da mesma forma que para os surrealistas, pode sim, ser fonte de inspiração e de visões".

Embora os surrealistas afirmem a suprarrealidade no agora, no momento presente, sem qualquer separação entre corpo, mente e espírito, é necessário um impulso rumo ao que Breton irá chamar de 'Maravilhoso', negando qualquer possibilidade de transcendência, mas apoiando-se na visão utópica e materialista de Karl Marx, de chegar a um porto ainda não alcançado, mítico, que de acordo com Chénieux-Gendron (1992, p. 120): “a força de imaginação e de representação que o mito traduz não é inferior a uma verdade de ordem conceitual. É outra. A sua verdade é alegórica. Há de um lado a representação e do outro o conceito". Há a mitificação do próprio inconsciente e dos desejos por parte dos surrealistas e, por parte da maioria

Figura 5 - René Magritte, The Dawn of Cayenne

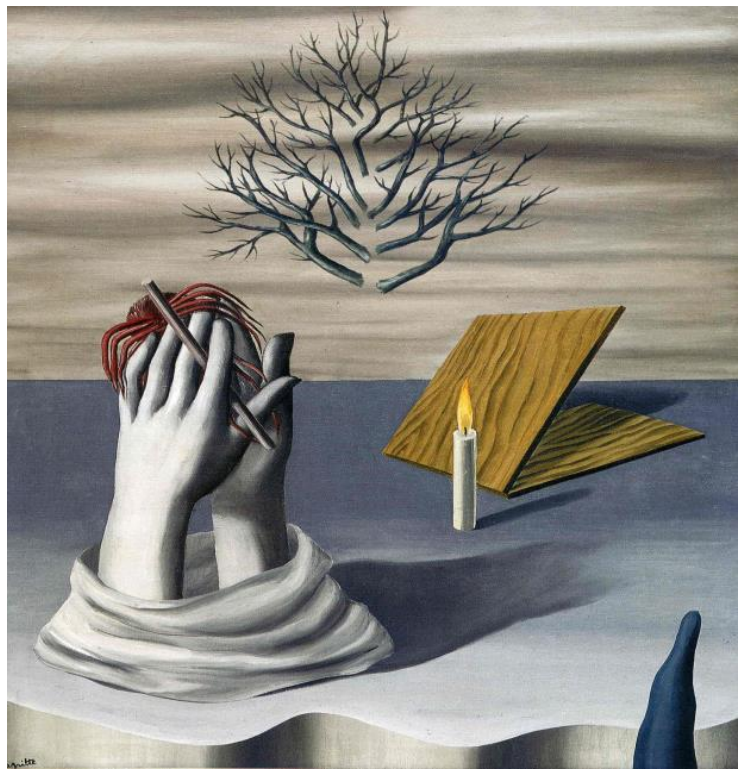

Fonte: Wikiart (2018).

Magritte traz o desprendimento racional rumo a uma paisagem onírica e no trabalho de Venosa se percebe uma tentativa de atingir um resultado dos visionários, de um todo espiritual. Segundo Chénieux-Gendron (1992, p. 126), embora “o propósito surrealista seja propor-nos uma narrativa, o que importa é o ajustamento de nossa ação à lição desse discurso. Esse discurso deve ser tal que suscite a nossa ação". Os visionários trazem à tona suas visões com o intuito de nos aproximar de algo invisível, mas que possa ser visto através da obra, ou seja, acreditam na potência de transformação da arte, mas por um caminho diferente. O que parece oposto pode se complementar ou se tratar apenas de diferenças engendradas na linguagem.

De acordo com as reflexões apresentadas até aqui, e partindo para uma apreciação dos aspectos formais, da temática e das fontes de inspiração para os artistas, podemos perceber as diferenças entre o Surrealismo e a Arte Visionária se compararmos uma pintura de René Magritte com uma de Robert Venosa, porexemplo:

\section{Figura 6 - Enlightenment}

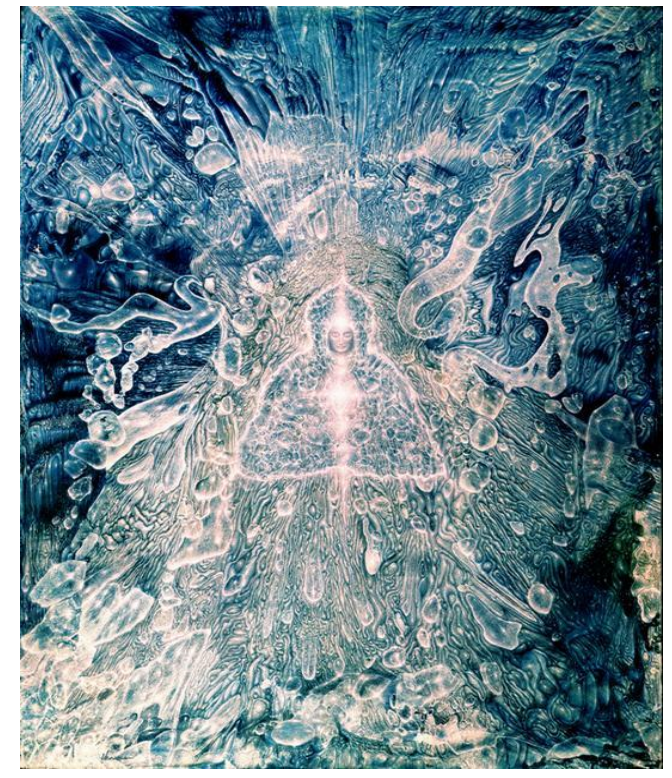

Fonte: Venosa (2018). semelhante ao que possa ter sido experienciado em algum estado não ordinário de consciência, através das cores e formas que se mesclam em 
um todo luminoso, um fluxo de energias. Em Magritte encontramos o surrealista trabalhando o desprendimento das travas da razão, enquanto que em Venosa, o que é representado é a imagem advinda de alguma visão de seu mundo espiritual, também percebido devido a uma figura central em posição meditativa e o título Enlightenment (Iluminação).
Figura 7 - Pablo Amaringo, Huarmi Taquina

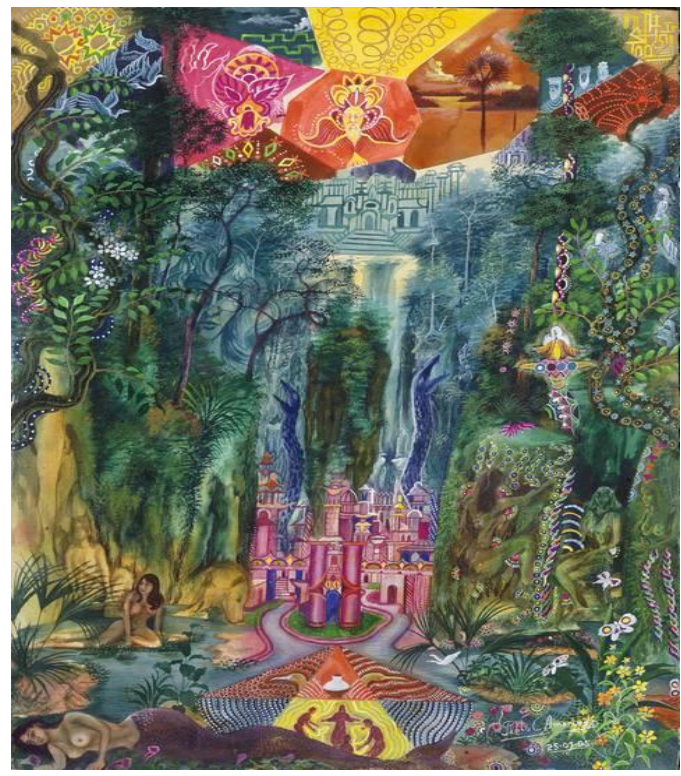

Fonte: (Fine Art America (2018).
Figura 8 - The Eye Of Silence

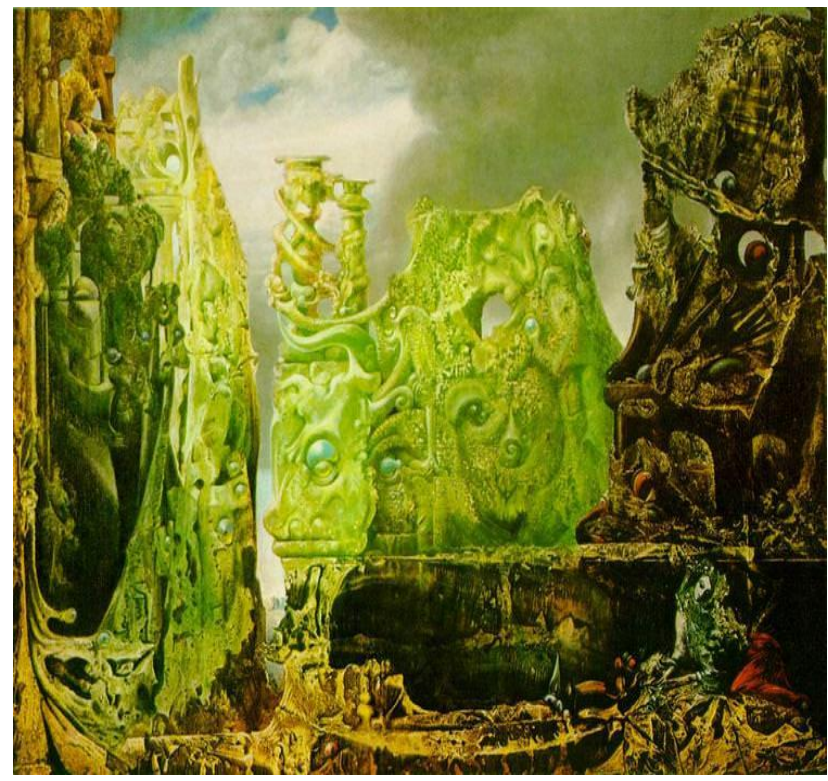

Fonte: Ernest (2018).
Neste outro exemplo, Pablo Amaringo, artista visionário peruano, representa suas visões, chamadas de 'mirações', experienciadas em rituais religiosos onde se consome a bebida amazônica Ayahuasca, também bastante presente aqui no Brasil, utilizada por povos indígenas e outras religiões. E o artista Max Ernst, como descrito por De Micheli (2004, p. 168), parece até elaborar "uma visão ficcionista em escala poética. Passado e futuro reúnem-se em suas imagens, ruínas arcaicas e árvores antropomorfas, pássaros de antracita e sóis prismáticos".

Em ambas as obras podemos observar muitas ondulações, espirais, objetos e seres se mesclando e se metamorfoseando, planos que se sobrepõem e cores vibrantes em dégradés minuciosos e formas fractais, efeitos muito similares aos de estados não ordinários de consciência. Talvez Max Ernst se diferencie enquanto surrealista devido aproximação de realidades distantes, utilizando-se de recursos formais, e não a representação direta de uma visão interior, ainda que possa haver alguma inspiração em ENOC.

Os visionários, de maneira geral, não encaram suas visões enquanto alucinações, mas sim enquanto experiências genuínas, diferentemente dos surrealistas que criavam suas imagens interessados pela loucura, pelo místico, mas a uma distância segura, embora se saiba que no começo do movimento surrealista houve alguns experimentadores de substâncias psicoativas, mas nada que nos revele um aprofundamento ou grande interesse no assunto, prezando pela aleatoriedade do pensamento, como dito por Chénieux-Gendron (1992, p. 201): 
Certamente a extrema concentração voluntária alcança em seus efeitos fantasísticos a extrema liberdade do espírito abandonado aos azares da escolha. O efeito alucinatório é garantido pelo desenraizamento sistemático. A poucas páginas de distância, Max Ernst emprega as mesmas palavras "intensificação súbita das faculdades visionárias", que nasce do próprio absurdo do ajuntamento.

E também em Caruana (2013, p. 1) sobre o uso de psicoativos:

"Onde os surrealistas tentaram, através do estado onírico, se elevar às mais altas realidades (e contra o uso de psicoativos) os artistas visionários usam tudo a sua disposição - mesmo com grande risco pessoal - para acessar diferentes estados de consciência e expor as visões resultantes".

Como dito anteriormente, a arte visionária talvez perpasse toda a história da arte, pois “através dos ENOC, o artista visionário encontra modos diferenciados de perceber os trabalhos de arte tradicional. Muitas mensagens inesperadas escondidas previamente ou 'despercebidas' emergem, agora, expandindo nossa percepção da história da arte" (MIKOSZ, 2014, p. 96). Dentro do movimento surrealista, pode ter havido artistas que possam ser considerados visionários, como Max Ernst, citado anteriormente e Salvador Dali, como podemos ver em De Micheli (2004, p. 163) sobre o método de Dali em referência ao de Max Ernst:

Essa primeira intuição de Ernst será desenvolvidaporSalvador Dalícomasuateoria da imagem múltipla ou imagem paranoica. $\mathrm{Na}$ realidade, mais do que uma teoria, trata-se de uma atividade visionária, que se reporta aos fenômenos da paranoia. Segundo Dalí, trata-se justamente de uma atividade paranoico-crítica, ou seja, do "método espontâneo de conhecimento irracional baseado na associação interpretativo-crítica dos fenômenos do delírio

Seu método paranoico-crítico de alguma forma induzia-o a ter visões, e pode ser considerado uma forma de ENOC, e que logo iria ser o fator condicionante para suas representações, como ainda segundo De Micheli (2004, p. 163):

Entende-se, observa Breton, "que, no caso de Dalí, estamos lidando com uma paranoia latente, da espécie benigna, a paranoia de planos latentes isolados, cuja evolução está a salvo de todo e qualquer perigo de confusão". Em Dalí, enfim, as imagens paranoicas logo que surgem são controladas, organizadas, utilizadas "criticamente.

Como dito por Caruana anteriormente, um ENOC pode ser experienciado em uma simples enxaqueca e causar visões internas, e a Arte Visionária não consiste em representar as visões durante o ENOC, mas sim estar condicionado a representação inspirada no ENOC, após sua experiência, o que muitas levam os artistas a organizarem, controlarem, por vezes de maneira crítica a forma como irão representar aquilo que foi visto e experienciado previamente, racionalizando o irracional, ou espiritual. E remetendo a questão da interioridade para os surrealistas, relacionado a infância e os desejos, é possível estabelecer um paralelo sobre os ENOC, segundo Caruana (2013, p. 16):

Os portões para 'a experiência visionária infernal' podem se abrir, de repente, a qualquer momento. Devido aos traumas inerentes à própria vida - acidentes, doenças, perdas pessoais ou separações repentinas - formas temporárias de loucura, paranoia ou psicose podem ocorrer, acompanhadas por visões e alucinações sem controle. Essas podem assumir a forma de uma regressão involuntária de memória, na tentativa de descobrir a fonte do nosso trauma. Regredir para as nossas primeiras memórias pode trazer a recordação dos terrores espontâneos da infância, fantasias e medos. As primeiras telas surrealistas de Dali oferecem uma série de temas, sendo cada tela uma tentativa para descobrir o seu maior medo, tormento e desejo proibido. 
A obra A Ascensão de Cristo pode ser um bom exemplo, se pensarmos nas comparações anteriores, e na linha tênue que é o limiar entre o Surrealismo e a Arte Visionária. De acordo com texto em Dalipaintings (2018), Dali disse que sua inspiração veio de um sonho cósmico que teve em 1950, onde viu o núcleo que um átomo, sob sua musa inspiradora Gala que se encontra derramando lágrimas, e o compreendeu como a verdadeira representação do espírito unificador de Cristo. Sobre os aspectos formais pode ser percebido as ondulações e luminosidades típicas de ENOC, quase como as presentes na obra citada de Robert Venosa, espirais, uma figura mandálica e forte conotação espiritual.

Figura 9 - Salvador Dali, The Ascension of Christ

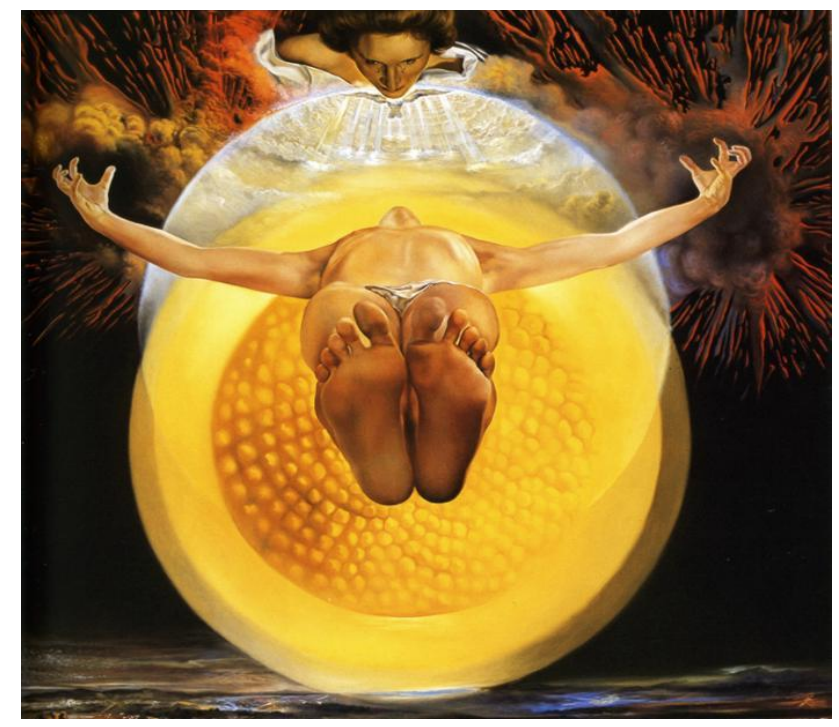

Fonte: DaliPaintings (2018).

\section{Considerações Finais}

AArte Visionária é a arte de se representar visões, não visões do mundo físico, cognoscível, mas de um universo interior, desconhecido, novo. Há Arte Visionária desde a arte pré-histórica, as catedrais barrocas, até a grande diversidade contemporânea, mas um período de grande repressão parece ter afastado os artistas das experiências visionárias, o que foi pouco a pouco sendo resgatado no decorrer da história, e podemos ver o Surrealismo como um grande contribuinte para esse resgate, pois foi um movimento que contribuiu para o olhar para si mesmo, para dentro, abrindo espaço para uma nova Arte Visionária que surge na contemporaneidade.

O voltar-se para dentro, o que chamamos de desconhecido, é um ponto em comum, mas encarado na maioria das vezes dentro da espiritualidade pelos visionários. Há milênios muitas das tradições espirituais são sustentadas pelo olhar interior, a atenção plena, a meditação, o autoconhecimento, mas os surrealistas encaram a experiência interior como uma tomada de consciência dos fluxos psicofisiológicos, como uma análise mental que suscite ações a fim de subverter as relações das coisas.

Os aspectos formais nas duas formas de arte, a questão estética, é o que mais diretamente as aproxima, como foi possível perceber, a grande necessidade de se representar algo novo, a partir de uma experiência com algo até então desconhecido, e o rigor técnico para se alcançar o máximo da representação. Os elementos formais, principalmente 
as distorções, ondulações e metamorfoses estão quase sempre presentes em ambas. E ainda, há um novo encantamento da vida, o maravilhoso, para os surrealistas, e a revelação da espiritualidade para os visionários. Ambos acreditam que a realidade não se limita ao mundo externo, visível e cognoscível, contudo, para os surrealistas não há nada para além do próprio homem enquanto que para os visionários há uma espiritualidade que transcende o humano. Em ambas as formas de arte há um despertar de uma nova consciência diante da vida, e uma forte intenção em se representar essa experiência formalmente.

Algumas das experiências dos surrealistas podem ser consideradas ENOC, pois nem todo ENOC é de cunho espiritual, logo, alguns artistas surrealistas ou trabalhos individuais podem ser considerados visionários. Como dito anteriormente, um trabalho visionário está condicionado a uma experiência prévia com ENOC, e não é realizado durante a experiência, mas depois, às vezes após longo tempo, a experiência será representada de alguma forma, sendo fonte de inspiração para o trabalho.

Tratar de assuntos não racionais de maneira racional e aproximá-los do meio acadêmico, que exige uma linguagem científica, é uma tarefa que exige grande aprofundamento, por isso, esta pesquisa pode ser um impulso a uma gama de possíveis e novas pesquisas dentro das Artes Visuais, e também, uma apresentação sucinta do próprio Surrealismo, já bastante difundido, e da Arte Visionária, tema ainda pouco pesquisado.

\section{Referências}

BRETON, A. Manifestos do surrealismo. Rio de Janeiro: Nau, 2004.

CARUANA, L. O primeiro manifesto da arte visionária. Curitiba: URCI-GLP, 2013.

CHÉNIEUX-GENDRON, J. O surrealismo. São Paulo: M. Fontes, 1992.

DALIPAINTINGS. Salvador Dali Paintings, Biography, and Quotes. The ascension of Christ, 1958 by Salvador
Dali. Disponível em: <https://www.dalipaintings.com/ the-ascension-of-christ.jsp>. Acesso em: 1 mar, 2018.

DE MICHELI, M. As vanguardas artísticas. São Paulo: M. Fontes, 2004.

ERNST, M. Max Ernst, and his paintings. Disponível em: $<$ http://www.max-ernst.com/index.jsp $>$. Acesso em: 1 mar. 2018.

FER, B. Realismo, racionalismo, surrealismo: surrealismo, mito e psicanálise. São Paulo: Cosac \& Naify, 1998. Cap. 3.

FINEARTAMERICA. Pablo Amaringo: Huarmi Taquina. Disponível em: <https://fineartamerica.com/ featured/huarmi-taquina-pablo-amaringo.html $>$. Acesso em: 1 mar. 2018.

MIKOSZ, J. E. Arte visionária: representações visuais inspiradas nos estados não ordinários de consciência (ENOC). Curitiba: Prismas, 2014.

SAGE, A. Ana-Suromai. Disponível em: <http:// amandasage.com/2011/08/ana-suromai/>. Acesso em: 1 mar. 2018.

TAMANI, L. Flor de tabaco. Disponível em: <https:// www.luis-tamani.com/gallery?lightbox=image_232r>. Acesso em: 1 mar. 2018.

TATE. Artists in the Collection. Artworks. Joan Miró: painting: 1927. Disponível em: <http://www.tate.org.uk/ art/artworks/miro-painting-t01318>. Acesso em: 1 mar. 2018.

VENOSA, R. LE 15. Enlightenment. Disponível em: $<$ http://www.venosa.com/enlighte.html $>$. Acesso em: 1 mar. 2018.

WIKIART. Visual Art Encyclopedia. Rene Magritte: the dawn of Cayenne: 1926. Disponível em: <https:// www.wikiart.org/en/rene-magritte/the-dawn-ofcayenne-1926>. Acesso em: 1 mar. 2018.

WIKIART. Visual Art Encyclopedia. Ernst Fuchs: transformations of flesh: 1949. Disponível em: <https:// www.wikiart.org/en/ernst-fuchs/transformations-offlesh-1949>. Acesso em: 1 mar. 2018. 
